\title{
Ret/PTC activation does not influence clinical and pathological features of adult papillary thyroid carcinomas
}

Efisio Puxeddu, Sonia Moretti, Angela Giannico ${ }^{1}$, Marco Martinelli, Cecilia Marino, Nicola Avenia ${ }^{2}$, Roberto Cristofani ${ }^{2}$, Raffaele Farabi ${ }^{3}$, Gianpaolo Reboldi, Rodolfo Ribacchi ${ }^{1}$, Alfredo Pontecorvi ${ }^{4}$ and Fausto Santeusanio

Department of Internal Medicine, ${ }^{1}$ 2nd Chair of Pathology, ${ }^{2}$ Department of Surgical Sciences, and ${ }^{3}$ Institute of Pathology R, University of Perugia, Perugia, Italy and ${ }^{4}$ Laboratory of Molecular Oncogenesis, Regina Elena Cancer Institute and Institute of Medical Pathology, Catholic University, Rome, Italy

(Correspondence should be addressed to Efisio Puxeddu, Dipartimento di Medicina Interna, Sezione di Medicina Interna e Scienze Endocrine e Metaboliche, via E. dal Pozzo, 06126 Perugia, Italy; Email: efisio@dimisem.med.unipg.it)

\begin{abstract}
Objective: RET proto-oncogene rearrangements (ret/PTCs) represent the most common genetic alterations found in papillary thyroid carcinomas (PTCs). Correlation of ret/PTC expression with clinical outcome is controversial. The aim of the present study was to analyze the frequency of RET rearrangements in adult PTCs, and to investigate if ret/PTCs influence biological behavior and clinical features of the cancers.

Design: Ret/PTC rearrangements were looked for in tissue samples of 48 PTCs collected at our institution. Data about clinical and pathological features of the tumors were also reviewed. Three separate association analyses were carried out on the cohort evaluating the effects of, respectively, ret/PTC positivity, preferential RET tyrosine kinase domain (RET-TK) expression, and ret/PTC plus RET-TK positivity, on age, sex, tumor size, staging, number of neoplastic foci, and histological subtype.

Methods: The genetic study was conducted with the RT-PCR-Southern blot technique. Standard Student's $t$-test and Fisher exact test were applied for the association analyses.

Results: The molecular genetic study demonstrated the positivity of ret/PTC1 and ret/PTC3 in 13 of 48 tumors $(27.1 \%)$, and an exclusive or preferential RET-TK expression in 17 cases $(35.4 \%)$. None of the three genetico-clinical analyses showed any significant association between ret/PTC expression and the clinical and pathological features of the cancers.

Conclusions: These data indicate that RET rearrangements may not play any distinctive role in driving histotype development and cancer progression in these neoplasms. Moreover, they weaken the possibility of using ret/PTC as a prognostic marker for papillary thyroid carcinomas.
\end{abstract}

European Journal of Endocrinology 148 505-513

\section{Introduction}

The RET proto-oncogene encodes a membrane tyrosine kinase receptor involved in the transduction of several signals for development, growth, differentiation and migration of neural crest-derived cell lineages $(1,2)$. RET proto-oncogene rearrangements represent the most common genetic alterations found in papillary thyroid carcinomas (PTCs). Moreover, there is evidence to indicate that they are an early genetic event in PTC development (2). These rearrangements derive from the fusion of the RET tyrosine kinase domain sequence with the $5^{\prime}$ sequences of heterologous genes, which creates chimeric oncogenes named ret/PTCs. They comprise 3 main forms, ret/PTC1, 2 and 3, of which
ret/PTC1 and 3 are definitely more frequent $(3-7)$, and several other rare variants recently described mainly in thyroid cancers from areas contaminated by the Chernobyl nuclear accident, as well as ret/PTC4, ret/PTC5, ret/PTC6, ret/PTC7, ret/KTN1, ret/RFG8, ret/PCM-1, and ret/ELKS (8).

Ret/PTC1 arises from a paracentric inversion of the long arm of chromosome 10 which creates the fusion oncogene D1OS170(H4)-RET, owing to the peculiar breakpoints in the regions of RET tyrosine kinase domain and of D10S170 (probe H4) (9). Ret/PTC2 is formed by a recombination between chromosomes 10 and 17 in which gene portions coding for the RET tyrosine kinase domain (RET-TK) and for the promoter of $\mathrm{RI} \alpha$ regulatory subunit of cAMP-dependent protein 
kinase A form a chimeric gene (10). Finally, ret/PTC3, like ret/PTC1, derives from a paracentric inversion of the long arm of chromosome 10 which juxtaposes the RET tyrosine kinase domain to the $5^{\prime}$ portion of the gene ELE1 (6). All these fusion proteins are characterized by a cytoplasmic constitutive activation of the tyrosine kinase function (10), which plays a transforming activity as demonstrated in in vitro experiments (11) and in transgenic mice models $(12-14)$.

The prevalence of these rearrangements in sporadic PTC from adult subjects varies widely in different studies $(2.5-44 \%)(15-17)$, due to genetic and/or environmental factors and to methodological differences applied in their search. In pediatric PTCs the prevalence is definitely higher (48-65\%) (16-18). But the highest prevalence was reported with pediatric thyroid carcinomas associated with radiation exposure from the Chernobyl nuclear accident (67-87\%) $(17-19)$.

One of the most intriguing problems with these rearrangements is their clinical significance. Indeed, correlation between ret/PTC rearrangements and biological behavior of the tumors has been controversial. Some report the association of ret/PTC with aggressive disease (19-22), while others associate ret/PTC with small tumor size and better prognosis (23-25).

In this study, we investigated retrospectively the prevalence of RET rearrangements (both as ret/PTC1 and 3 expression and as the preferential expression of RET-TK, marker of all potential RET rearrangements) in a sporadic thyroid carcinoma cohort collected at our center between 1995 and 1999, and correlated the molecular genetic results with the clinical and pathological features of the tumors, trying to understand which role, if any, ret/PTC plays in papillary thyroid carcinoma progression.

\section{Materials and methods}

\section{Patient population}

Forty-eight cases of sporadic papillary thyroid carcinoma from Italian patients aged 22-80 years were studied. Twenty-five were consecutive cases treated surgically between July 1997 and June 1999 at the Institutes of Thoracic Surgery and Oncologic Surgery of the University of Perugia, for which fresh frozen tumor tissues were available. The remaining 23 cases were selected from a consecutive series of 25 PTCs collected between October 1995 and July 1997, which were stored in the files of the Institute of Pathology of our institution. In these cases the material available was paraffin-embedded tissue and they were selected on the basis of the availability of RNA of sufficient integrity to allow genetic analysis.

In 45 cases the only tissue sample analyzed was from the primary tumor, in one case it was exclusively from a metastatic lymph node. Moreover, in two cases we analyzed samples both from the primary tumor and from corresponding lymph node metastases.

The medical records relative to the hospitalization for the thyroidectomy of each patient were reviewed to obtain data about possible radiation exposure, age at diagnosis, and sex.

\section{Histology}

Histological slides from the thyroid tumors stained by hematoxylin and eosin were reviewed by at least two pathologists ( $\mathrm{R} \mathrm{F}$ and $\mathrm{R} \mathrm{R}$ ) to confirm the diagnoses, define the pathological $\mathrm{T}$ and $\mathrm{N}$ stage $(\mathrm{pT}$ and $\mathrm{pN}$ ), and subclassify the variants of papillary carcinomas. In detail, we divided the tumors into two main categories, 'high grade' (including the diffuse sclerosing variant, the tall cell variant and poorly or undifferentiated cancers) and 'low grade', as described previously (26). Moreover, in the low grade group we distinguished two main subtypes, solid/follicular and classic papillary.

\section{Genetic analysis}

RNA was obtained from fresh frozen tissues as described by Chomczynski and Sacchi (27). In the 23 paraffin-embedded samples RNA was extracted from two unstained $20-\mu \mathrm{m}$ thick sections containing at least $70 \%$ of tumor tissue, as reported previously (28). In order to exclude the possibility of sample cross contamination during the RNA extraction process, and of RNA or cDNA sample contamination by PCR products present in the laboratory environment, for every five tissue samples we prepared a control sample of the extraction reagents which was submitted to reverse transcription and to all the PCR reactions as an additional negative control. Reverse transcription of either $1 \mu \mathrm{g}$ total RNA or, in the case of RNA extracted from paraffin-embedded samples, half of the recovered nucleic acids, was conducted at $37^{\circ} \mathrm{C}$ with an avian myeloblastoosis virus reverse transcriptase (Finnzymes OY, Espoo, Finland), using a random examers mixture as a primer (New England BioLabs, Beverly, MA, USA), in a total volume of $20 \mu \mathrm{l}$. The obtained cDNA was first tested to ensure that the integrity of the RNA was sufficient for analysis. For this purpose a 661-bp sequence of the $\beta$-actin cDNA was amplified using primers spanning an exon-exon junction of the gene (29) (Table 1). Only those samples demonstrating clearly detectable levels of the transcript on an ethidium bromide-stained agarose gel were further analyzed (25/25 of fresh frozen tissue samples and 23/25 of paraffin-embedded tissue samples).

All the adequate cDNAs were submitted in the first instance to two PCR reactions using sets of primers designed to amplify the regions bracketing chimeric sequences of the ret/PTC1 and ret/PTC3 rearrangements (18) (Table 1). Secondly, we tested the samples with primers for the boundaries of exon $7 / 8$ 
Table 1 Primers used for PCR.

\begin{tabular}{|c|c|c|c|}
\hline & Size $(b p)$ & Primer sequences $\left(5^{\prime}-3^{\prime}, a-s e n s e, b\right.$-antisense $)$ & Probes for hybridization $\left(5^{\prime}-3^{\prime}\right)$ \\
\hline$\beta$-actin & 661 & $\begin{array}{l}\text { a-TGACGGGGTCACCCACACTGTGCCCATCTA } \\
\text { b-CTAGAAGCATTGCGGTGGACGATGGAGGG }\end{array}$ & \\
\hline Ret/PTC1 & 165 & $\begin{array}{l}\text { a-GCTGGAGACCTACAAACTGA } \\
\text { b-GTTGCCTTGACCACTTTTC }\end{array}$ & GGCACTGCAGGAGGAGAACCGCGA \\
\hline Ret/PTC3 & 242 & $\begin{array}{l}\text { a-AAGCAAACCTGCCAGTGG } \\
\text { b-CTTTCAGCATCTTCACGG }\end{array}$ & GGTCGGTGCTGGGTATGTAAGGA \\
\hline RET-TK & 155 & $\begin{array}{l}\text { a-GGAGCCAGGGTCGGATTCCAGTTA } \\
\text { b-CCGCTCAGGAGGAATCCCAGGATA }\end{array}$ & ACGCAAAGTGATGTATGGTCT \\
\hline RET-EC & 184 & $\begin{array}{l}\text { a-GGCGGCCCAAGTGTGCCGAACTT } \\
\text { b-CCCAGGCCGCCACACTCCTCACA }\end{array}$ & GGTCGGTGCTGGGTATGTAAGGA \\
\hline Calcitonin & 302 & $\begin{array}{l}\text { a-GGACTATGTGCAGATGAAGG } \\
\text { b-TAGGAAGGATGCAAGAAGGG }\end{array}$ & \\
\hline
\end{tabular}

(extracellular domain, RET-EC) and exons 16/17 (RETTK) of the RET gene (20) (Table 1). The exclusive or preferential expression of the TK domain was considered indicative of TK activation typical of RET rearrangements $(16,18)$.

For each PCR, $2 \mu \mathrm{l}$ of the reverse transcribed mixture were amplified with $50 \mathrm{pmol}$ of each primer, $200 \mu \mathrm{mol} / \mathrm{l}$ deoxynucleotide triphosphates, $10 \mathrm{mmol} / \mathrm{l}$ Tris- $\mathrm{HCl}\left(\mathrm{pH} \quad 8.8\right.$ at $\left.25^{\circ} \mathrm{C}\right), \quad 1.5 \mathrm{mmol} / \mathrm{l} \mathrm{MgCl}_{2}$, $150 \mathrm{mmol} / \mathrm{l} \mathrm{KCl}, 0.1 \%$ Triton X-100, and $2 \mathrm{U}$ Dynazyme II DNA polymerase (Finnzymes Oy, Espoo, Finland) in a final volume of $50 \mu \mathrm{l}$. For $\beta$-actin, after $5 \mathrm{~min}$ hotstart at $99^{\circ} \mathrm{C}, 35$ cycles of denaturation $\left(95^{\circ} \mathrm{C}\right.$ for $1 \mathrm{~min})$, annealing $\left(60^{\circ} \mathrm{C}\right.$ for $\left.1 \mathrm{~min}\right)$, and extension $\left(72{ }^{\circ} \mathrm{C}\right.$ for $1 \mathrm{~min}$ and $\left.30 \mathrm{~s}\right)$ were conducted on a Hybaid PCR Sprint thermal cycler (Hybaid, Ashford, Kent, UK). For ret/PTCs, after $5 \mathrm{~min}$ hot-start at $99^{\circ} \mathrm{C}$, four cycles of 'touch-down' amplification were performed (progressively lowering the annealing temperature from $61^{\circ} \mathrm{C}$ to $57^{\circ} \mathrm{C}$ ), followed by 40 cycles of regular amplification $\left(95^{\circ} \mathrm{C}\right.$ for $1 \mathrm{~min}, 57^{\circ} \mathrm{C}$ for $1 \mathrm{~min}$, and $72^{\circ} \mathrm{C}$ for $\left.1 \mathrm{~min}\right)$. Finally, for RET-TK and RET-EC, $5 \mathrm{~min}$ of hot-start at $99{ }^{\circ} \mathrm{C}$ were followed by 14 cycles of 'touch-down' amplification $\left(64^{\circ} \mathrm{C}-57^{\circ} \mathrm{C}\right)$ and 27 cycles of regular amplification $\left(95^{\circ} \mathrm{C}\right.$ for $1 \mathrm{~min}, 57^{\circ} \mathrm{C}$ for $1 \mathrm{~min}$, and $72^{\circ} \mathrm{C}$ for $\left.1 \mathrm{~min}\right)$. Positive controls for amplifications included cDNA samples from two PTCs, one positive for ret/PTC1 and one for ret/PTC3 (the latter kindly provided by Dr R Elisei, University of Pisa), and from a medullary thyroid carcinoma with constitutive expression of wild-type RET (for amplification of RET-TK and RET-EC).

Ten microliters of the PCR products of ret/PTC1, ret/PTC3, RET-TK and RET-EC were electrophoresed in a $1.8 \%$ agarose gel and blotted to a nylon membrane (Schleicher and Schuell, Legnano, Italy). Each filter was then hybridized overnight at $50{ }^{\circ} \mathrm{C}$ with the indicated probe end-labeled with ${ }^{32} \mathrm{P}$ (18) (Table 1), washed, and analyzed using a phosphoimager system (Instant Imager, Camberra-Packard, Meriden, CT, USA).

In cases \#2, \#9, \#11, \#12, \#17, and \#19, which tested positive for both RET-TK and RET-EC at comparable levels, we performed an additional PCR reaction using primers for calcitonin (CT) (Table 1) to test for CT expression as a marker of C-cell contamination of the tumor samples. The reaction was conducted applying the same program used for $\beta$-actin (annealing temperature $60^{\circ} \mathrm{C}$ ). As a positive control the cDNA from a medullary thyroid carcinoma was used, and the specificity of the bands obtained was verified by sequence analysis.

\section{Analysis of ret/PTC PCR sensitivities}

In order to compare the sensitivities of the PCR reactions used to detect ret/PTC1, ret/PTC3 and RET-TK, in the first instance we performed the reactions using as templates serial dilutions (from $1 \mathrm{pg}$ to $10^{-6} \mathrm{pg}$ ) of plasmids containing the full-length cDNAs of ret/PTC1 and ret/PTC3. Moreover, in order to quantify the minimal number of ret/PTC-positive tumor cells necessary to obtain a ret/PTC amplicon, we performed PCR reactions for ret/PTC1, followed by Southern blotting, on the cDNA obtained from cell mixtures of serially diluted TPC-1 cells (expressing ret/PTC1) with NIH-3T3 cells (TPC-1/NIH-3T3: $10^{7} / 0,10^{6} / 9 \times 10^{6}$, $10^{5} / 9.9 \times 10^{6}, 10^{4} / 9.99 \times 10^{6}, 10^{3} / 9.999 \times 10^{6}$, $\left.10^{2} / 9.9999 \times 10^{6}, 10 / 9.99999 \times 10^{6}, 0 / 10^{7}\right)$.

TPC-1 and NIH-3T3 cells were grown in Dulbecco's modified eagle medium (GIBCO, Paisley, Scotland, UK) with the addition of $5 \%$ fetal bovine serum (GIBCO) and penicillin/streptomycin (GIBCO). RNA extraction, cDNA synthesis, PCR and Southern blot were performed as described above (see Genetic analysis).

\section{Statistical analysis}

Results are presented as means \pm S.D. or as a percentage with 95\% confidence intervals (CI) as appropriate, calculated using the Poisson distribution. Continuous variables were compared by two-tailed unpaired Student's $t$-test. The Fisher exact test was used to determine two-tailed $P$ values in $2 \times 2$ contingency tables. $P$ values $<0.05$ were considered significant. 


\section{Results}

\section{Clinical and pathological characteristics}

Forty-eight thyroid carcinomas from 32 women and 16 men were examined (Table 2). The average age at surgery was 45.6 years (range 22-80 years), while the average tumor size was $2 \mathrm{~cm}$ (range $0.5-4 \mathrm{~cm}$ ). Nine patients presented with a microcarcinoma (diameter $\leq 1 \mathrm{~cm}$ ) and 20 had multifocal disease. No patient had an apparent history of neck irradiation. At the time of diagnosis, 20 cases presented with a pathological T4 stage and 17 with a pathological N1 stage. Morphological diagnosis revealed six high grade papillary carcinomas (including one tall cell variant, one diffuse sclerosing variant, two poorly differentiated cancers and two cancers with anaplastic dedifferentiation) and 42 low grade cancers. The low grade tumors included 25 solid/follicular cancers, 16 classic papillary cancers, and one Hürthle cell PTC.

Table 2 Summary of clinical data. Results are means (range) or number (percentage).

\begin{tabular}{lc}
\hline Clinico-pathological features & Number \\
\hline Sex (F:M) & $32: 16$ \\
Mean age (years) & $45.6(22-80)$ \\
Mean tumor size $(\mathrm{cm})$ & $2(0.5-4)$ \\
Diameter $\leq 1 \mathrm{~cm}$ & $9(19.5 \%)$ \\
pT4 & $20(42.5 \%)$ \\
pN1 & $17(35.4 \%)$ \\
Multifocality & $20(42.5 \%)$ \\
High grade & $6(12.5 \%)$ \\
Low grade & \\
Solid/follicular & $25(52 \%)$ \\
Classic papillary & $16(33.3 \%)$ \\
Others & $1(2.1 \%)$ \\
\hline
\end{tabular}

All the patients underwent total thyroidectomy and lymph node dissection of the enlarged lymph nodes singled out at surgery.

\section{Molecular genetic analysis}

RT-PCR followed by Southern blotting demonstrated the presence of ret/PTC1 and ret/PTC3 in 13 of 48 tumors $(27.1 \%, 95 \%$ CI $14.4-46.2)$. In detail, five cancers tested positive for ret/PTC1, five for ret/PTC3, and three simultaneously for ret/PTC1 and ret/PTC3 (Fig. 1).

The search of RET-TK and RET-EC expression showed 17 cases with an exclusive or preferential RET-TK expression (35.4\%, 95\% CI 20.6-56.7), six cases with both RET-TK and RET-EC expression, and 25 cases negative for both RET-TK and RET-EC expression (Fig. 1). Ten (76.9\%) of the ret/PTC-positive tumors presented, as expected, an exclusive or preferential RET-TK expression. However, three of them did not (Fig. 1). In detail, cases \#5 and \#16 did not show any RET-TK and RET-EC amplification, while case \#19 tested positive for both RET-TK and RET-EC at comparable levels. The remaining seven RET-TK-positive-ret/PTC1 and 3-negative tumors might represent cases characterized by the expression of minor ret/ PTCs. The contemporary RET-TK and RET-EC amplification could be related to $\mathrm{C}$-cell contamination of the PTC tissues only in sample \#2, which also showed expression of calcitonin (Fig. 2). On the other hand, samples \#9, \#11, \#12, \#17, and \#19 did not show any amplification for calcitonin (Fig. 2). Moreover, in sample \#9 the same RET-TK and RET-EC pattern was observed in a corresponding lymph node metastasis, where C-cell growth is highly unlikely (Fig. 1).

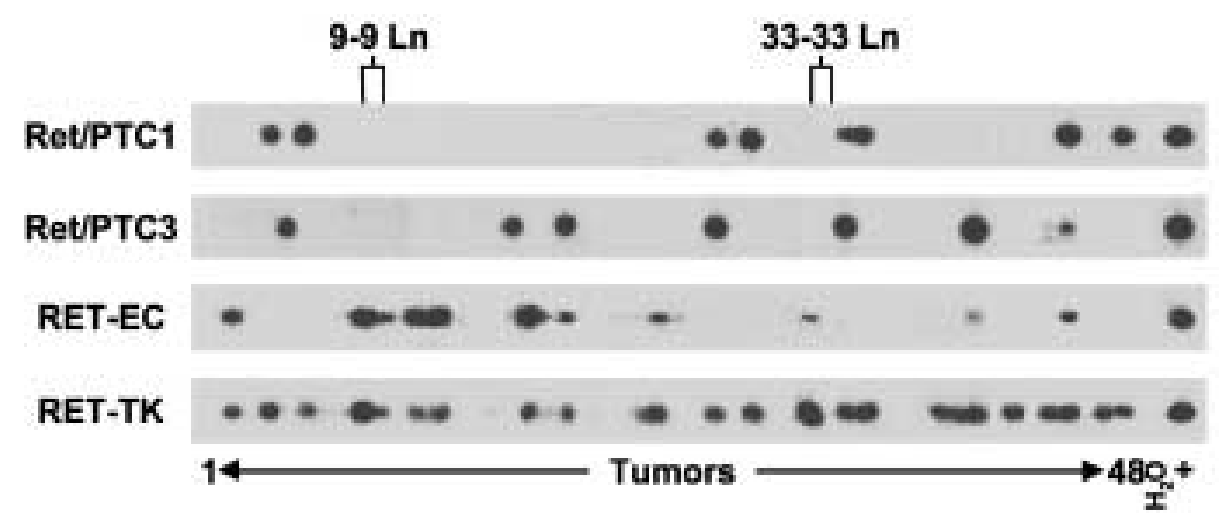

Figure 1 Results of the molecular genetic analysis. RT-PCR followed by Southern blotting demonstrated the expression of ret/PTC1 and ret/PTC3 in 13 out of 48 tumors: five cancers tested positive for ret/PTC1, five for ret/PTC3, and three simultaneously for ret/PTC1 and ret/PTC3. Sixteen cases showed an exclusive or preferential RET-TK expression, six cases both RET-TK and RET-EC expression, and 26 cases neither RET-TK nor RET-EC expression. For tumors \#9 and \#33, two tissue samples were available, one from the primary lesion and one from a lymph node metastasis (Ln) (see text). $\mathrm{H}_{2} \mathrm{O}, \mathrm{PCR}$ negative control; +, PCR positive control. 


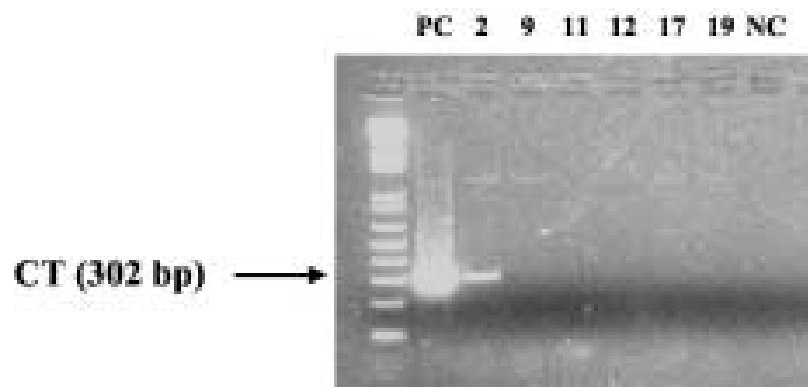

Figure 2 Analysis of calcitonin expression in samples positive for RET-TK and RET-EC at comparable levels. RT-PCR for calcitonin (CT) showed amplification only in sample \#2, while samples \#9, \#11, \#12, \#17, and \#19 were negative for the C-cell marker. PC, positive control, represented by the cDNA derived from a medullary thyroid carcinoma; NC, negative control.

\section{Genetico-clinical analysis}

In the first instance three separate genetico-clinical analyses were carried out on the cohort depending on the positivity of ret/PTC1 and 3, or on the preferential expression of RET-TK, or on the positivity of ret/PTC1 and 3 and/or RET-TK. None of these three analyses showed any significant association between ret/PTC expression (evaluated either as ret/PTC1 and ret/PTC3 positivity, or as preferential RET-TK expression) and the different clinical and pathological parameters considered (age, sex, tumor size, pT, pN, number of tumor foci, histological subtype as well as high grade cancers, solid-follicular variants of PTC, classic papillary variants of PTC) (Table 3, panels A and B and C).

Moreover, we looked for the presence of an association between distinct ret/PTC rearrangements (ret/PTC1, ret/PTC3, simultaneous ret/PTC1 and 3 expression, potential new alternative ret/PTCs (RETTK-positive-ret/PTC-negative cases)) and the tumor features. This analysis also did not show any peculiar genetico-clinical association, with the exception of the finding of 3 multifocal tumors out of 3 in the simultaneously ret/PTC1 and 3-positive PTCs (Table 3, panel D).

\section{Analysis of ret/PTC PCR sensitivities}

The analysis of ret/PTC and RET-TK PCR efficiencies showed at least a 1000 times higher sensitivity of ret/PTC1 PCR and a 10 to 100 times higher sensitivity of ret/PTC3 PCR, compared with the PCR for RET-TK (Fig. 3A and B). Moreover, for ret/PTC1 we calculated that the minimum number of positive tumor cells necessary to detect the rearrangement was equivalent to one positive cell in $10^{6}$ negative cells (Fig. 3C).

\section{Discussion}

The activation of several oncogenes and the loss of function of some tumor suppressor genes have been shown in thyroid tumors of follicular origin. However, the importance of each of these genes in the carcinogenic process has not been completely elucidated. Ret/PTC are very interesting oncogenes both for their relatively high expression frequency in PTCs $(16,17)$ and for their well known property of being precocious inductors of thyroid carcinogenesis $(2,11-14,23)$. Unfortunately, little is known about their role in papillary thyroid cancer progression, and in any case about their role as potential new molecular prognostic markers of the disease.

The aim of our work was to study the prevalence of ret/PTC in a cohort of adult PTCs collected in our region and to search for correlations between the molecular genetic results and several clinical and pathological features of the cancers.

In our series, ret/PTC1 and 3 rearrangements were found in 13 of $48(27.1 \%)$ adult PTCs, a prevalence slightly lower than that reported in other Italian studies of comparable size $(17,21,30)$. This observation should be related to the genetic diversity of the studied population or to a difference in thyroid carcinoma etiological factors present in our region, where most of the patients are from, and not to a lack of sensitivity of the applied technique, as demonstrated by the finding that for RET/PTC1 the RT-PCR-Southern blot method allowed the detection of up to 1 positive cell diluted in $10^{6}$ negative cells and that the PCR for ret/PTC3 allowed the detection of minimal amounts, as low as $10^{-4} \mathrm{pg}$, of a positive control plasmid.

The use of primers only for the chimeric sequences of ret/PTC1 and 3 did not allow us to evaluate the specific expression of minor ret/PTCs, such as ret/PTC2. For this reason we submitted the cDNA samples to another two PCR reactions with primers designed to amplify regions in the RET-EC and RET-TK domains, considering the exclusive or preferential expression of RET-TK to be a general indicator of RET activation through a chromosomal rearrangement. Seventeen cases showed an exclusive or at least a preferential expression of RET-TK (35.4\%), six cases tested positive for both RET-TK and RET-EC, and 25 cases did not show any amplification. Ten of the 17 RET-TK-positive tumors were also positive for ret/PTC1, or for ret/PTC3, or for both. The remaining seven RET-TK-positiveret/PTC1 and 3-negative tumors might represent PTCs characterized by the expression of less frequent ret/PTCs, as well as ret/PTC2 or other more recently identified ret/PTCs (8). The simultaneous positivity for RET-TK and RET-EC could be related to C-cell contamination in only one of the PTC samples. Indeed, in five cases the absence of amplification for calcitonin excluded the presence of C-cells. Moreover, we had one cDNA sample from a lymph node metastasis which showed RET-TK and RET-EC expression superimposable on that observed in the corresponding primary tumor. These data suggest the possibility of wild-type RET proto-oncogene expression in a subgroup of 


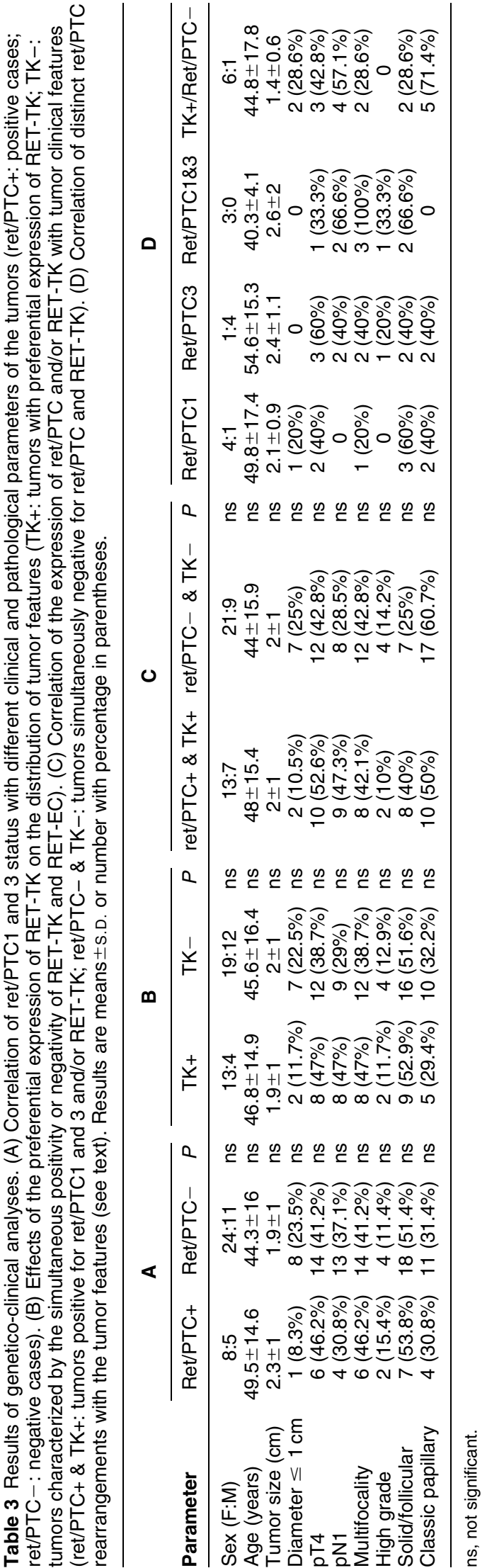

thyroid cancers of follicular origin, as already proposed by other groups $(31,32)$.

There is great interest in finding genetic markers that predict the behavior of thyroid tumors, as histological and clinical features may fail to do so. The value of ret/PTCs as prognostic factors is still controversial. Some authors report the association of RET rearrangements with aggressive disease (19-22), while others associate them with small tumor size and better prognosis (23-25). Moreover, three recent studies could not show any significant difference between ret/PTC-positive and ret/PTC-negative cancers, either in terms of clinical features or in terms of histotype distribution $(17,31,33)$. In this study, we investigated the presence of associations between the expression of RET rearrangements and several clinical and pathological features of the tumors known to play a role in the prognostic stratification of thyroid cancers. We were unable to find any significant association either with ret/PTC1 and 3 expression or with RET-TK preferential expression. These data do not exclude the possibility that RET activation may play a role as an independent prognostic factor, which could be evaluated only after the follow-up of a sufficient number of patients for a sufficient time to have a significant number of tumor relapses and cancer-related deaths. However, they seem to indicate, at least, that ret/PTCs may not specifically influence local aggressiveness and histotype development in PTCs occurring spontaneously in an adult population.

Three of our 13 ret/PTC-positive cases did not show any preferential RET-TK expression. These tumors may represent a group of cancers characterized by a lower ret/PTC expression, confined only to some cells, so that the more sensitive search for ret/PTC proved positive, while the search for RET-TK proved negative. A large variability in the level of ret/PTC expression in PTCs has already been described, and recently higher ret/PTC expression was found in tumors of patients with low risk clinical parameters and lymphatic involvement $(34,35)$. In our hands this was not the case, as a sub-analysis performed moving the ret/PTCpositive-TK-negative cases to the ret/PTC-negative group (data not shown) did not give us any significant association between ret/PTC expression and the clinical and pathological features of the tumors.

Finally, the search for an association with specific RET rearrangements (ret/PTC1, ret/PTC3, ret/PTC1 and 3 , and potential new alternative ret/PTCs) showed only a potential association between multifocality of the tumor and the simultaneous expression of ret/PTC1 and $3(100 \%$ of ret/PTC1 and 3-positive cases were multifocal against a prevalence of $20-40 \%$ multifocal lesions in the other groups). Independently of the lack of statistical significance for the low number of cases, this last observation was interesting, because there is still debate about the origin of multifocal tumor lesions. A recent paper 
A

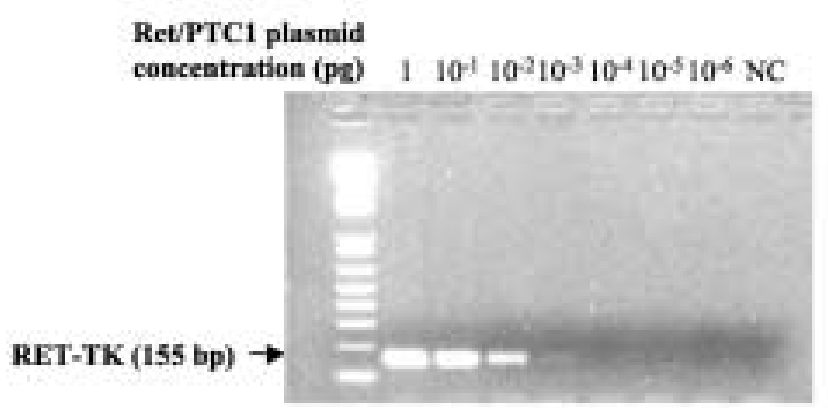

Ret/PTC1 (165 bp) $\rightarrow$
B
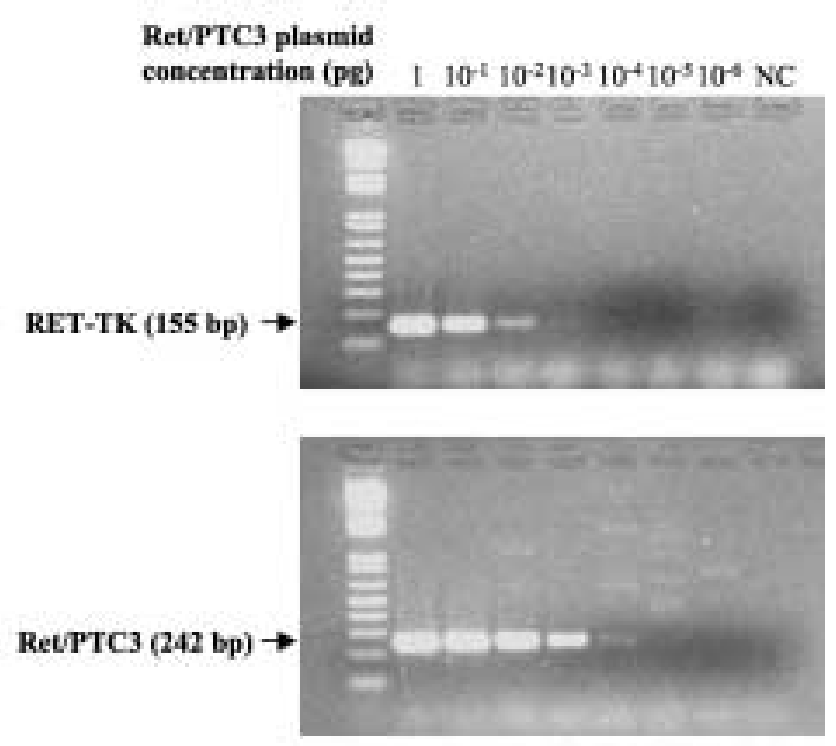

$\mathrm{C}$

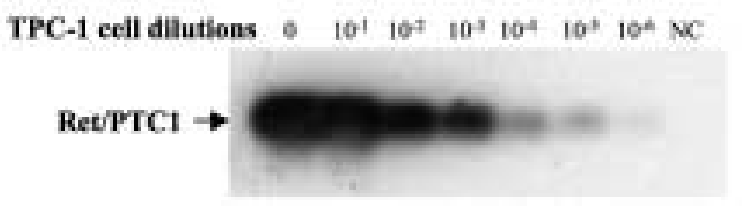

Figure 3 Analysis of ret/PTC and RET-TK PCR sensitivities. (A) Comparison of the sensitivities of the PCRs for RET-TK and ret/PTC1, using as templates serial dilutions of a plasmid containing the full-length CDNA of the oncogene, showed that the PCR for ret/PTC1 was at least 1000 times more sensitive than the PCR for RET-TK. NC, negative control. (B) Comparison of the sensitivities of the PCRs for RET-TK and ret/PTC3, using as templates serial dilutions of a plasmid containing the full-length cDNA of the oncogene, showed that the PCR for ret/PTC3 was 10 to 100 times more sensitive than the PCR for RET-TK. NC, negative control. (C) Quantification of ret/PTC1 PCR absolute sensitivity showed that the minimum number of ret/PTC1-expressing TPC-1 cells necessary to detect the rearrangement was equivalent to one positive cell in $10^{6}$ negative cells (NIH-3T3 cells). Zero represents the result obtained with non diluted TPC-1 cells, while the values $10^{-1}-10^{-6}$ refer to the dilution of TPC-1 cells in NIH-3T3 cells. NC, negative control.

pointed out that in multifocal disease individual tumors, characterized by diversity in ret/PTC profiles, arise independently (36). Our data, showing the highest prevalence of multifocal thyroid carcinomas in the group of tumors expressing simultaneously ret/PTC1 and 3, seem to confirm the possibility of a multiclonality of multifocal disease.

In summary, we were unable to find any significant association between the expression of RET rearrangements, evaluated either as ret/PTC1 and 3 or preferential RET-TK expression, and several clinical pathological features of PTCs. Moreover, we were unable to find any potential association between the tumor features considered and the expression of specific RET rearrangements. Our data may indicate that RET rearrangements, although essential for the development of a subgroup of papillary thyroid carcinomas (11-14), do not play any significant distinctive role in driving the histotype development and the progression, in terms of local invasive capacity, of these neoplasms. We hypothesize that other genetic events may be needed in addition to ret/PTC activation for the expression of a complete malignant phenotype and for cancer progression. Alternatively, we propose that ret/PTCs may have the same non specific weight in PTC development and progression as other alternative genetic events involved in follicular cell carcinogenesis. Both these hypotheses weaken the possibility of using ret/PTC as a valuable molecular genetic prognostic marker for papillary thyroid 
carcinomas occurring spontaneously in the adult population.

\section{References}

1 Takahashi M, Buma Y, Iwamoto T, Inaguma Y, Ikeda H \& Hiai H. Cloning and expression of the RET proto-oncogene encoding a tyrosine kinase with two potential transmembrane domains. Oncogene $19883571-578$.

2 Puxeddu E \& Fagin JA. Genetic markers in thyroid neoplasia. Endocrinology and Metabolism Clinics of North America 200130 493-513.

3 Grieco M, Santoro M, Berlingieri MT, Melillo RM, Donghi R, Bongarzone I et al. PTC is a novel rearranged form of RET proto-oncogene and is frequently detected in vivo in human thyroid papillary carcinomas. Cell 199060 557-563.

4 Bongarzone I, Monzini N, Borrello MG, Carcano C, Ferraresi G, Arighi E et al. Molecular characterization of a thyroid tumorspecific transforming sequence formed by the fusion of RET tyrosine kinase and the regulatory subunit RI $\alpha$ of cyclic AMPdependent protein kinase A. Molecular and Cell Biology 199313 358-366.

5 Jhiang SM, Smanik PA \& Mazzaferri EL. Development of a singlestep duplex RT-PCR detecting different forms of RET activation, and identification of the third form of in vivo RET activation in human papillary thyroid carcinoma. Cancer Letter $1994 \mathbf{7 8}$ $69-76$.

6 Bongarzone I, Butti MG, Coronelli S, Borrello MG, Santoro M, Mondellini $\mathrm{P}$ et al. Frequent activation of RET proto-oncogene by fusion of a new activating gene in papillary thyroid carcinomas. Cancer Research 199454 2979-2985.

7 Santoro M, Dathan NA, Berlingieri MT, Bongarzone I, Paulin C, Grieco M et al. Molecular characterization of RET/PTC3; a novel rearranged version of the RET proto-oncogene in a human thyroid papillary carcinoma. Oncogene 19949 509-516.

8 Nikiforov YE. RET/PTC rearrangement in thyroid tumors. Endocrine Pathology 200213 3-16.

9 Pierotti MA, Santoro M, Jenkins RB, Sozzi G, Bongarzone I, Grieco $\mathrm{M}$ et al. Characterization of an inversion on the long arm of chromosome 10 juxtaposing D1OS170 and RET and creating the oncogenic sequence RET/PTC. PNAS 199289 1616-1620.

10 Lanzi C, Borrello MG, Bongarzone I, Migliazza A, Fusco A, Grieco $\mathrm{M}$ et al. Identification of the product of two oncogenic rearranged forms of the RET proto-oncogene in papillary thyroid carcinomas. Oncogene $199272189-2194$.

11 Santoro M, Melillo RM, Grieco M, Berlingieri MT, Vecchio G \& Fusco A. The TRK and RET tyrosine kinase oncogenes cooperate with RAS in the neoplastic transformation of a rat thyroid cell line. Cell Growth and Differentiation 19934 77-84.

12 Jhiang SM, Sagartz JE, Tong Q, Parker-Thornburg J, Capen CC, Cho JY et al. Targeted expression of the RET/PTC1 oncogene induces papillary thyroid carcinomas. Endocrinology 1996137 375-378.

13 Santoro M, Chiappetta G, Cerrato A, Salvatore D, Zhang L, Manzo $\mathrm{G}$ et al. Development of papillary thyroid carcinomas secondary to tissue-specific expression of RET/PTC1 oncogene in transgenic mice. Oncogene $1996121821-1826$.

14 Powell DJ Jr, Russell J, Nibu K, Li G, Rhee E, Liao M et al. The RET/PTC3 oncogene: metastatic solid-type papillary carcinomas in murine thyroids. Cancer Research 199858 5523-5528.

15 Zou M, Shi Y \& Farid NR. Low rate of RET proto-oncogene activation (PTC/RET/PTC) in papillary thyroid carcinomas from Saudi Arabia. Cancer 199473 176-180.

16 Williams GH, Rooney S, Thomas GA, Cummins G \& Williams ED. RET activation in adult and childhood papillary thyroid carcinoma using a reverse transcriptase-n-polymarase chain reaction approach on archival-nested material. British Journal of Cancer $199674585-589$.
17 Elisei R, Romei C, Vorontsova T, Cosci B, Veremeychik V, Kuchinskaya E et al. RET/PTC rearrangements in thyroid nodules: studies in irradiated and not irradiated, malignant and benign thyroid lesions in children and adults. Journal of Clinical Endocrinology and Metabolism 200186 3211-3216.

18 Nikiforov YE, Rowland JM, Bove KE, Monforte-Munoz H \& Fagin JA. Distinct pattern of RET oncogene rearrangements in morphological variants of radiation-induced and sporadic thyroid papillary carcinomas in children. Cancer Research 199757 1690-1694.

19 Rabes HM, Demidchik EP, Sidorow JD, Lengfelder E, Beimfohr C, Hoelzel D et al. Pattern of radiation-induced RET and NTRK1 rearrangements in 191 post-Chernobyl papillary thyroid carcinomas: biological, phenotypic, and clinical implications. Clinical Cancer Research 20006 1093-1103.

20 Jhiang SM, Caruso DR, Gilmore E, Ishizaka Y, Tahira T, Nagao M et al. Detection of PTC/retTPC oncogene in human thyroid cancers. Oncogene 19927 1331-1337.

21 Bongarzone I, Vigneri P, Mariani L, Collini P, Pilotti S \& Pierotti MA. RET/NTRK1 rearrangements in thyroid gland tumors of the papillary carcinoma family: correlation with clinicopathological features. Clinical Cancer Research 19984 223-228.

22 Thomas GA, Bunnell H, Cook HA, Williams ED, Nerovnya A, Cherstvoy ED et al. High prevalence of RET/PTC rearrangements in Ukrainian and Belarussian post-Chernobyl thyroid papillary carcinomas: a strong correlation between RET/PTC3 and the solid-follicular variant. Journal of Clinical Endocrinology and Metabolism $1999 \mathbf{8 4} 4232-4238$.

23 Viglietto G, Chiappetta G, Martinez-Tello FJ, Fukunaga FH, Tallini G, Rigopoulou D et al. RET/PTC oncogene activation is an early event in thyroid carcinogenesis. Oncogene 199511 $1207-1210$.

24 Tallini G, Santoro M, Helie M, Carlomagno F, Salvatore G, Chiappetta G et al. RET/PTC oncogene activation defines a subset of papillary thyroid carcinomas lacking evidence of progression to poorly differentiated or undifferentiated tumor phenotypes. Clinical Cancer Research 19984 287-294.

25 Soares P, Fonseca E, Wynford-Thomas D \& Sobrinho-Simoes M. Sporadic RET-rearranged papillary carcinoma of the thyroid: a subset of slow growing, less aggressive thyroid neoplasms? Journal of Pathology $1998 \mathbf{1 8 5} 71-78$.

26 Rosai J, Carcangiu ML \& Delellis RA. Tumors of the thyroid gland. In Atlas of Tumor Pathology, third series, vol. 5, pp 65-121. Ed. J Rosai. Washington, DC: Armed Forces Institute of Pathology, 1992.

27 Chomczynski P \& Sacchi N. Single-step method of RNA isolation by acid guanidium thiocyanate-phenol-chloroform extraction. Annals of Biochemistry 1987162 156-159.

28 Shimizu H \& Burns JC. Extraction of nucleic acids: sample preparation from paraffin-embedded tissues. In PCR Strategies, pp 32-38. Eds MA Innis, DH Gelfand \& JJ Sninsky. San Diego: Academic Press, 1995.

29 Ehlers S \& Smith KA. Differentiation of T cell lymphokine gene expression: the in vitro acquisition of T cell memory. Journal of Experimental Medicine 1991173 25-36.

30 Santoro M, Grieco M, Melillo RM, Fusco A \& Vecchio G. Molecular defects in thyroid carcinomas: role of the RET oncogene in thyroid neoplastic transformation. European Journal of Endocrinology 1995 $133513-522$.

31 Learoyd DL, Messina M, Zedenius J, Guinea AI, Delbridge LW \& Robinson BG. RET/PTC and RET tyrosine kinase expression in adult papillary thyroid carcinomas. Journal of Clinical Endocrinology and Metabolism $1998 \mathbf{8 3} 3631-3635$.

32 Fluge O, Haugen DR, Akslen LA, Marstad A, Santoro M, Fusco A et al. Expression and alternative splicing of $c$-RET RNA in papillary thyroid carcinomas. Oncogene 200120 885-892.

33 Nikiforov YE, Erickson LA, Nikiforova MN, Caudill CM \& Lloyd RV. Solid variant of papillary thyroid carcinoma: incidence, clinicalpathologic characteristics, molecular analysis, biologic behavior. American Journal of Surgical Pathology 200125 1478-1484. 
34 Sugg SL, Zheng L, Rosen IB, Freeman JL, Ezzat S \& Asa SL. RET/PTC1, 2, and 3 oncogene rearrangements in human thyroid carcinomas: implication for metastatic potential? Journal of Clinical Endocrinology and Metabolism 199681 3360-3365.

35 Mayr B, Brabant G, Goretzki P, Ruschoff J, Dietmaier W \& Dralle H. RET/PTC1, 2, and 3 oncogene rearrangements in human thyroid carcinomas: implication for metastatic potential? Journal of Clinical Endocrinology and Metabolism 199782 1306-1307.
36 Sugg SL, Ezzat S, Rosen IB, Freeman JL \& Asa SL. Distinct multiple RET/PTC gene rearrangements in multifocal papillary thyroid neoplasia. Journal of Clinical Endocrinology and Metabolism 1998 83 4116-4122.

Received 29 October 2002

Accepted 5 February 2003 